\title{
Does the disabilities of the arm, shoulder and hand (DASH) scoring system only measure disability due to injuries to the upper limb?
}
A. S. Dowrick, B. J. Gabbe, O. D. Williamson, P. A. Cameron

From Monash University, Melbourne, Australia

A. S. Dowrick, MAppSc, PhD Scholar

B. J. Gabbe, MAppSc, PhD, Research Fellow

O. D. Williamson, MBBS,

FRACS, Orthopaedic Surgeon

In P. A. Cameron, MD, FACEM,

Professor and Head of Pre-

Hospital, Emergency and

Trauma Group

Department of Epidemiology and Preventive Medicine

Monash University, Central and

Eastern Clinical School, Alfred

Hospital, Commercial Road,

Melbourne, Victoria 3004,

Australia.

Correspondence should be sent to Professor P. A. Cameron;

e-mail: Peter.Cameron@

med.monash.edu.au

(C2006 British Editorial Society of Bone and Joint Surgery doi:10.1302/0301-620X.88B4. $17223 \$ 2.00$

$J$ Bone Joint Surg [Br] 2006;88-B:524-7.

Received 22 September 2005; Accepted after revision 17 November 2005

\begin{abstract}
Although the Disabilities of the Arm, Shoulder and Hand (DASH) questionnaire was designed, and has been validated, as a measure of disability in patients with disorders of the upper limb, the influence of those of the lower limb on disability as measured by the DASH score has not been assessed. The aim of this study was to investigate whether it exclusively measures disability associated with injuries to the upper limb. The Short Musculoskeletal Functional Assessment, a general musculoskeletal assessment instrument, was also completed by participants. Disability was compared in 206 participants, 84 with an injury to the upper limb, 73 with injury to the lower limb and 49 controls.
\end{abstract}

We found that the DASH score also measured disability in patients with injuries to the lower limb. Care must therefore be taken when attributing disability measured by the DASH score to injuries of the upper limb when problems are also present in the lower limb. Its inability to discriminate clearly between disability due to problems at these separate sites must be taken into account when using this instrument in clinical practice or research.

Traumatic injuries commonly involve the upper $\operatorname{limb}^{1}$ and can cause problems in performing the activities of daily living. ${ }^{2}$ However, there are few published data on the functional outcome following such injuries and no consensus has been reached regarding a standardised method of measurement, making comparison between studies and/or injuries difficult. ${ }^{3,4}$

The Short Musculoskeletal Functional Assessment (SMFA), a general musculoskeletal instrument, and the Disabilities of the Arm, Shoulder and Hand (DASH) scoring system, a means of assessing function in the upper limb, are frequently used to assess self-reported patient outcomes in orthopaedics. ${ }^{5-12}$ The SMFA has not been used in studies of isolated injury to the upper limb, although it does contain items that appear specific to arm and hand function. Although both SMFA and DASH are commonly used to measure disability in patients following acute injuries, they have been validated mainly in patients with chronic disorders.

The aim of this study was to investigate the validity of the SMFA and DASH in patients following trauma to the upper and lower limbs to determine whether the DASH measures disabilities which can be solely attributed to the former. It was hypothesised that, when using the SMFA, patients with injuries to the upper and lower limbs would record significantly higher scores than the controls, who would score close to zero. It was also felt that when using the DASH questionnaire, patients with injuries to the upper limb would record significantly higher scores than those with problems with the lower limb and the controls, who would both score close to zero.

\section{Materials and Methods}

Participants were recruited from an orthopaedic outpatient clinic at an adult Level 1 trauma centre, between May and November 2004. The inclusion criteria were: presentation to an outpatient clinic with an isolated injury to the upper or lower limb, aged over 17 years and living at home at the time of recruitment. The controls were individuals attending the clinic without having sustained an injury in the past six months and who were accompanying someone presenting with a limb injury. All participants were living in Australia at the time of recruitment. Individuals who had been diagnosed with a psychological illness or dementia, or were unable to complete the questionnaires because of cognitive impairment or language difficulties were excluded. Written informed consent was obtained from all participants.

The SMFA is a self-reported 46-item questionnaire consisting of two parts: a dysfunction index (34 items) and a bother index (12 items). 
Table I. Source of data variables

\begin{tabular}{ll}
\hline Data obtained from medical records & $\begin{array}{l}\text { Data obtained from } \\
\text { patient }\end{array}$ \\
\hline Date of birth & $\begin{array}{l}\text { Current status } \\
\text { Comorbidities }\end{array}$ \\
Conder & Marital status \\
Comorbidities & Occupation \\
Injury date & Occupational time fraction \\
Incident details & Hand dominance \\
Injury description & Recreation and hobbies $^{*}$ \\
Date of diagnosis & Level of education $^{\dagger}$ \\
Diagnosis of side & SMFA $^{\dagger}$ \\
Description of injury & DASH $^{\ddagger}$ \\
Orthopaedic management description & Date of birth $^{\S}$ \\
Implant used (if applicable) &
\end{tabular}

* obtained via patient interview

† SMFA, Short Musculoskeletal Functional Assessment dysfunction index ‡ DASH, Disabilities of the Arm, Shoulder and Hand

$\S$ obtained via interview for control group

The dysfunction index is grouped into four domains: daily activities, emotional status, arm and hand function and mobility. Each item is scored using a five-point scale ranging from 'not at all difficult' to 'unable to do'. The bother index assesses how much the patient is troubled by problems associated with broad functional areas and also uses a five-point scale. Scores range from 0 to 100 , with higher scores indicating a poorer level of function. ${ }^{13}$ Because we were interested in assessing functional outcome related to the activities of daily living, we only used the dysfunction index of the SMFA.

The DASH questionnaire is a regional outcome measure suitable for patients with musculoskeletal conditions of the upper limb and consists of 30 items. ${ }^{4}$ Six domains are assessed: daily activities, symptoms, social function, work function, sleep and confidence. Each item in the daily activ- ities domain is scored on a five-point scale, from 'no difficulty' to 'unable to do'. The other domains are also scored on a five-point scale. The scores for all items are used to calculate a total ranging from 0 (no disability) to 100 (severe disability). ${ }^{14}$

Approval to screen medical records of the patients was granted by the ethics committee of the hospital. This process was performed by the primary author (ASD) on the afternoon before the clinic to identify those patients who met the inclusion criteria. Eligible patients were invited to participate while waiting for their appointment. If an uninjured family member or friend accompanied the patient, he or she was invited to take part as a member of the control group.

Consenting participants completed a demographic questionnaire, the SMFA and the DASH instruments. The documentation took approximately 20 minutes to complete. Data pertaining to injury and details of treatment of the consenting participants was obtained from their medical records during this time (Table I). Questionnaires were selfcompleted by the majority of patients. Where participants with upper limb injuries were unable to write their responses, an accompanying person acted as a scribe. The data in Table I, obtained from the patient by interview, were collected once the participant had completed the questionnaires.

Missing data were treated as recommended by the developers of each instrument. For the SMFA dysfunction index, providing that more than $50 \%$ of the items were completed for each category, missing data were replaced by the individual's mean score for that particular category. ${ }^{13}$ For the DASH, at least 27 of the 30 items must be completed; $;^{15}$ missing items were left blank and the completed responses were added together and averaged. ${ }^{15}$

Table II. Demographics of the study participant

\begin{tabular}{|c|c|c|c|c|c|}
\hline Patient characteristics & Upper limb ( $n=84)$ & Lower limb ( $n=73$ ) & Control (n = 49) & Test & p value \\
\hline \multicolumn{6}{|l|}{ Age } \\
\hline Median (range) & $32.0(19 \text { to } 85)^{*}$ & $29.0(19 \text { to } 77)^{\dagger}$ & 51.0 (21 to 80$)$ & Kruskal-Wallis & $<0.001$ \\
\hline \multicolumn{6}{|l|}{ Gender } \\
\hline Male (\%) & 56 & 52 & 37 & Chi-squared & 0.09 \\
\hline \multicolumn{6}{|l|}{ Time since injury (days) } \\
\hline Median (range) & 21.0 (2 to 178$)$ & 26.0 (2 to 164$)$ & not applicable & Mann-Whitney & 0.40 \\
\hline Type of injury (\%) & & & & Chi-squared & 0.13 \\
\hline Open fracture & 2.4 & 9.6 & not applicable & & \\
\hline Closed fracture & 89.3 & 83.6 & not applicable & & \\
\hline Fracture/dislocation & 4.8 & 2.7 & not applicable & & \\
\hline Dislocation & 3.5 & 1.4 & not applicable & & \\
\hline Soft-tissue injury & not applicable & 2.7 & not applicable & & \\
\hline \multicolumn{6}{|l|}{ SMFA $^{\S}$} \\
\hline Median (range) & $31(2 \text { to } 73)^{* \ddagger}$ & $44(3 \text { to } 71)^{\dagger}$ & $2(0$ to 36$)$ & Kruskal-Wallis & $<0.001$ \\
\hline \multicolumn{6}{|l|}{ DASH } \\
\hline Median (range) & $53(2 \text { to } 89)^{* \neq}$ & $29(0 \text { to } 83)^{\dagger}$ & $1(0$ to 46$)$ & Kruskal-Wallis & $<0.001$ \\
\hline \multicolumn{6}{|c|}{$\begin{array}{l}\text { * significant difference between upper limb and control using Mann-Whitney U test } \\
\text { † significant difference between lower limb and control using Mann-Whitney U test } \\
\text { ‡ significant difference between upper and lower limb using Mann-Whitney U test } \\
\text { § SMFA, Short Musculoskeletal Functional Assessment dysfunction } \\
\text { ๆ DASH, Disabilities of the Arm, Shoulder and Hand }\end{array}$} \\
\hline
\end{tabular}


Table III. Proportions for Short Musculoskeletal Functional Assessment dysfunction index (SMFA) quartiles by group (percentage)

\begin{tabular}{lccc}
\hline Quartile & Upper limb & Lower limb & Control \\
\hline First & $4.8^{*}$ & 11.1 & 83.7 \\
Second & $42.2^{* \dagger}$ & 9.7 & 14.3 \\
Third & $28.9^{*}$ & $31.9^{\dagger}$ & 2.0 \\
Fourth & $24.1^{\ddagger}$ & 47.2 & 0.0
\end{tabular}

* significant difference between upper limb and controls using MannWhitney $U$ test

† significant difference between lower limb and controls using MannWhitney $U$ test

‡ significant difference between upper and lower limb using MannWhitney $U$ test

Table IV. Proportions for Disabilities of the Arm, Shoulder and Hand (DASH) quartiles by group (percentage)

\begin{tabular}{lccc}
\hline Quartile & Upper limb & Lower limb & Control \\
\hline First & $2.4^{* \dagger}$ & 17.8 & 75.5 \\
Second & $19.0^{*}$ & 32.9 & 22.4 \\
Third & $26.2^{*}$ & $39.7^{\dagger}$ & 2.0 \\
Fourth & $52.4^{\ddagger}$ & 9.6 & 0.0 \\
\hline
\end{tabular}

* significant difference between upper limb and controls using MannWhitney U test

$\dagger$ significant difference between lower limb and controls using MannWhitney $U$ test

‡ significant difference between upper and lower limb using MannWhitney $U$ test

The Kruskal-Wallis, Mann-Whitney U and chi-squared tests were used to examine differences across the groups for demographic variables. Kruskal-Wallis and Mann-Whitney $\mathrm{U}$ tests were used to investigate differences in SMFA and DASH scores between the three groups. A significance level of $\mathrm{p}<0.05$ was used. All analyses were performed using SPSS version 12.0 (SPSS Inc., Chicago, Illinois). Quartiles were used to examine the spread for the scores on the functional instruments between the groups.

\section{Results}

A total of 206 participants completed the study; 84 with an injury to the upper limb, 73 to the lower limb, and 49 who were used as controls. Table II shows the demographics for the sample by participant group. The control group was significantly older than both the injury groups (Table II).

Median values for the SMFA were 31 (2 to 73 ) for the upper limb group, 44 ( 3 to 71) for the lower limb group and 2 (0 to 36) for the controls (Table II). Median values for the DASH were 53 (2 to 89) for the upper limb group, 29 (0 to 83) for the lower limb group and 1 (0 to 46) for the controls (Table II).

The lower limb group recorded significantly higher scores indicating greater disability in the SMFA than did the upper $\operatorname{limb}(\mathrm{z}=-2.8, \mathrm{p}=0.005)$ and control $(\mathrm{z}=-8.4$, $\mathrm{p}<0.001)$ groups. The scores in the upper limb group were also significantly higher than the control values for the SMFA $(\mathrm{z}=-8.6, \mathrm{p}<0.001)$ (Table II). This group displayed significantly higher disability according to the DASH than did the lower $\operatorname{limb}(\mathrm{z}=-6.0, \mathrm{p}<0.001)$ and control $(\mathrm{z}=$ $-9.3, p<0.001)$ groups (Table II). The lower limb scores were significantly higher than the control values for the DASH $(z=-7.1, p<0.001)$. These results did not differ when the outliers were removed from the control group and the data re-analysed.

When dividing the scores for the outcome instruments by quartiles, $4.8 \%$ of upper limb and $11.1 \%$ of lower limb patients recorded scores in the lowest quartile for the SMFA, indicating little or no disability (Table III). Additionally, $2.4 \%$ of upper limb and $17.8 \%$ of lower limb patients produced scores in the lowest quartile for the DASH, indicating little or no disability (Table IV). The proportion of controls with scores that were not in the lowest quartile for the SMFA was $16.3 \%$ for the SMFA (Table III) and $24.4 \%$ for the DASH (Table IV), indicating some disability in the uninjured controls.

\section{Discussion}

This paper provides a comparison of the SMFA and the DASH in patients with isolated injuries and in uninjured controls. The results show that when using both instruments, the controls score close to zero, indicating little selfreported disability, whereas both the upper limb and lower limb groups displayed higher scores, indicating that although the DASH was designed to measure disability in the upper limb, it also measures disability in patients with injuries in the lower limb.

The SMFA was designed for use in all musculoskeletal conditions, regardless of the body region. In using this instrument in a sample of patients with isolated upper and lower limb injury and controls it would be expected that the controls would score close to zero on the scale, indicating no disability, whereas patients with injuries would be expected to score higher, indicating varying degrees of disability in the activities of daily living. This was observed in the current study. These findings suggest that the aim of the designers of the SMFA to construct a general outcome assessment instrument applicable to all musculoskeletal disorders has been successful. By contrast, the DASH is a region-specific instrument designed to assess disability of the upper limb. Therefore, this assessment would be expected to show scores in patients with injuries in the upper limb which indicated disability in activities of daily living, but those with injuries to the lower limb and the control group would be expected to score values indicating no disability. This was not found in this study.

A review of the DASH items revealed few tasks that could be considered to rely solely on function in the upper limb. For example, a task such as turning a key or opening a jar involves the use of the lower limb to provide sufficient mobility for the subject to reach the door or the bench to perform the task, and to maintain stability of the trunk and shoulder girdle while performing the finer details of the task. The upper limb is unable to function independently of the lower limb when performing activities of daily living 
that require mobility and stability. Thus, any disability in the lower limb which interferes with mobility and stability can result in disability that can be measured by the DASH. In this study only seven patients with disability in the lower limb of $73(10 \%)$ scored zero while $82.2 \%$ of the group indicated some perceived disability, being in the upper three quartiles, when assessed by DASH.

The two groups of patients were found to be in the first quartile exhibiting little or no disability in a percentage of participants who would be expected to show higher levels of disability (Tables III and IV). This might be due to healing following the injury or to adaptation to limitations during healing. For example, a patient could adjust to the use of crutches for mobility to such an extent that they now regard this as normal. At the same time, the control group indicated some degree of disability, being in the second or third quartiles, for the SMFA and DASH in $16.3 \%$ and $24.4 \%$ of participants, respectively (Tables III and IV). The control group was significantly older than the two patient groups, making it possible that self-reported disability was due to the presence of pre-existing musculoskeletal conditions or neurological disorders. Although this is a limitation of the study, it would not have affected the interpretation of the results. An older control group would be expected to have a higher level of disability than age-matched controls, resulting in an underestimation of any difference in disability between the uninjured and the injured groups.

Another limitation of this study was that it only assessed patients with a single injury of the upper or lower limb. The effect of combinations of injuries on disability as measured by the SMFA and DASH was not studied. However, the purpose of this study was to investigate the construct validity of the DASH. To ascertain this, Stewart and Ware ${ }^{16}$ stated that it must be established that "the health measure relates to other measures in ways consistent with plausible hypotheses". A type of construct validity is tested with 'known groups' analyses in which patients' scores on health status measures are expected to vary on the basis of their 'group' membership. Therefore, the DASH, having been developed as an upper limb-specific instrument, would not be expected to indicate disability in patients with injuries to the lower limb. The DASH has been predominantly evaluated in patients with repetitive motion disorders. Our results, compiled from a sample of patients with traumatic injuries, indicate that the construct validity of the DASH may require further investigation in acutely-injured patients. Further studies may also determine whether specific items within the SMFA and DASH can differentiate the upper limb group from both the lower limb and the control groups.

Care must be taken in the selection and interpretation of outcome assessment instruments for use in patients following orthopaedic injuries. This is particularly important for clinicians or researchers who are assessing patients with multiple injuries involving both the upper and lower limbs, or in patients with co-existing musculoskeletal or neurological disorders.

The preparation of this article forms part of a larger project, the Victoria Orthopaedic Trauma Outcomes Registry, funded by the Victorian Trauma Foundation. Dr Gabbe was supported by a Public Health Research Fellowship from the National Health and Medical Research Council, Australia. The authors would like to thank Mr Elton Edwards for his assistance in conducting this study.

No benefits in any form have been received or will be received from a commercial party related directly or indirectly to the subject of this article.

\section{References}

1. Brinker MR, O'Connor DP. The incidence of fractures and dislocations referred for orthopaedic services in a capitated population. J Bone Joint Surg [Am] 2004;86-A 290-7.

2. Mkandawire NC, Boot DA, Braithwaite IJ, Patterson M. Musculoskeletal recovery 5 years after severe injury: Iong term problems are common. Injury 2002;33 111-15.

3. Baldry Currens JA. Evaluation of disability and handicap following injury. Injury 2000;31:99-106

4. Holbrook TL, Anderson JP, Sieber WJ, Browner D, Hoyt DB. Outcome after major trauma: discharge and 6-month follow-up results from the Trauma Recovery Project. J Trauma 1998;45:315-24.

5. McKee MD, Wild LM, Schemitsch EH. Midshaft malunions of the clavicle. J Bone Joint Surg [Am] 2003;85-A:790-7.

6. Gofton WT, MacDermid JC, Patterson SD, Faber KJ, King GJW. Functional outcome of AO Type C distal humeral fractures. J Hand Surg [Am] 2003;28:294-308.

7. Jupiter JB, Ring D. Treatment of unreduced elbow dislocations with hinged external fixation. J Bone Joint Surg [Am] 2002;84-A:1630-5.

8. Egol KA, Connor PM, Karunaker MA, et al. The floating shoulder: clinical and functional results. J Bone Joint Surg [Am] 2001;83-A:1188-94

9. Ring D, Perey BH, Jupiter JB. The functional outcome of operative treatment of united fractures of the humeral diaphysis in older patients. J Bone Joint Surg [Am] 1999;81-A:177-90.

10. Brown OL, DirschI DR, Obremsky WT. Incidence of hardware-related pain and its effect on functional outcomes after open reduction and internal fixation of ankle fractures. J Orthop Trauma 2001;15:271-74.

11. Anglen JO, Burd TA, Hendricks KJ, Harrison P. The "Gull Sign": a harbinger of failure for internal fixation of geriatric acetabular fractures. J Orthop Trauma 2003;17 625-34

12. Sanders DW, Busan M, Hattwick $\mathbf{E}$, et al. Functional outcomes following displaced talar neck fractures. J Orthop Trauma 2004;18:265-70.

13. Swiontkowski MF, Engelberg R, Martin DP, Agel J. Short musculoskeletal function assessment questionnaire: validity, reliability, and responsiveness. J Bone Joint Surg [Am] 1999;81-A:1245-60.

14. Hudak PL, Amadio PC, Bombardier C. Development of an upper extremity outcome measure: the DASH (Disabilities of the Arm, Shoulder, and Hand). Am J Ind Med 1996;29:602-8.

15. Solway S, Beaton DE, McConnell S, Bombardier C. The DASH outcome measure user's manual. Second ed. Toronto, Ontario: Institute for Work \& Health, 2002.

16. Stewart AL, Ware JE Jr, eds. Measuring functioning and well-being: the medical outcomes study approach. Durham: Duke University Press, 1992. 